American J. of Engineering and Applied Sciences 2 (4): 713-720, 2009

ISSN 1941-7020

(C) 2009 Science Publications

\title{
Prediction Studies for the Performance of a Single Cylinder High Speed Spark Ignition Linier Engine with Spring Mechanism as Return Cycle
}

\author{
${ }^{1}$ A.Z.M. Fathallah and ${ }^{2}$ R.A. Bakar \\ ${ }^{1}$ Department of Marine Engineering, \\ Institute Technology of Sepuluh Nopember, Surabaya, Indonesia \\ ${ }^{2}$ Automotive Excellent Center, Faculty of Mechanical Engineering, \\ University Malaysia Pahang Lebuhraya Tun Razak, 263000 Gambang, Kuantan, Pahang, Malaysia
}

\begin{abstract}
Problem statement: Most concepts of linear engines were constructed as opposed pistons with complicated control devise to drive the engines. The advantage of the engines was their high overall efficiency. Approach: Although the efficiency was higher than conventional engine, however, it did not be applied yet, because the design of these engines was not only difficult to fabricate, but also it has little chance to compete the traditional engines in the market. Spring is adopted as a return force of the piston movement technique. Results: The unique of using spring as return cycle is the main characteristic of these engines. However, stroke of the engine is not constant as in the traditional engine. The problem is that, the expansion stroke is depending on thrust force of piston. On the other hand, the engine needs to operate in variable speed and load. This study is a prediction of the performance of both rotational and linear engines. Conclusion/Recommendations: The result of the examination can be used as return cycle design data of a single cylinder linear engine with spring device. As a result, the spring mechanism can be adopted to be used as return cycle in linear engine.
\end{abstract}

Key words: Linear engine, spring, performance

\section{INTRODUCTION}

Alternative engines have been developed in University Malaysia Pahang (UMP) for several years. A single cylinder high speed linear SI engine is one of the projects in the Automotive Focus Group in UMP. There are so many studies of linear engines have been conducted by researchers. However, the research results are unreliable to produce the engine in the near future. Most of linear engine researches were of high technology product designs, especially control systems. They used electronic automatic control systems. The weakness of the linear engines is its high production cost and impacted competitiveness comparing with traditional engine product, so it still needs to pay more efforts.

The main problems of linear engine design are difficult to get start, return cycle, system control, maintenance and others ${ }^{[1,2]}$. The difficulty to control the piston motion, in particular stroke length and compression ratio, has been proved. This is due the fact that the combustion process in one cylinder drives the combustion will have high influence on the next compression $^{[3]}$. A single cylinder linear engine is one alternative to eliminate, in general, the weakness of linear engines. Spring has been developed to conduct return cycle. Spring technology, which used as part of dynamics forces of linear engine, could be adopted, because spring technique can be adopted from cam valve device. It is expected, by this method, the difficulties of start and control systems can be reduced.

The problem is the difficulty of designing the system with a spring as return cycle. Also it is difficult to control the stroke. However, engine should be operated on variable speed and variable load. For electrical generator, the load is important because always it changes with the time. Engine load will affect the performance including combustion process and pressure of combustion chamber. The pressure of combustion chamber produces thrust force; this force will transfer to spring. The spring compressing force will be divided by spring constant (k) to get the engine stroke $(x=F / k)$. The small load results in small pressure of combustion chamber, because $\mathrm{k}$ is constant; so the stroke will be small. On the other hand, if the load increases, it will increase the engine stroke. For that reason, it is need to design the spring precisely; otherwise the scavenging process can not work effectively.

Corresponding Author: A.Z.M. Fathallah, Department of Marine Engineering, Institute Technology of Sepuluh Nopember, Surabaya, Indonesia Tel: +60169637250 Fax: +6095492244 


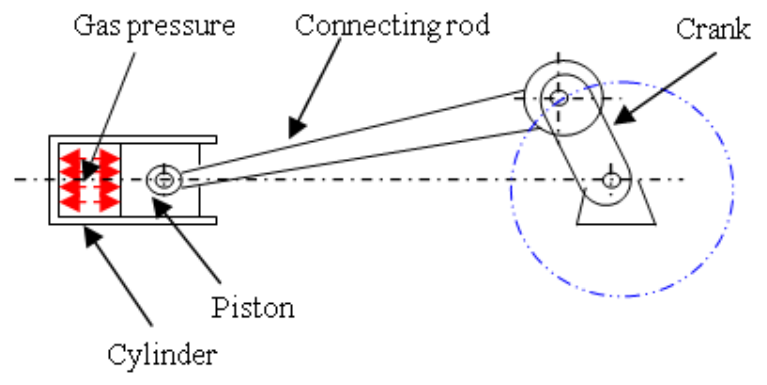

Fig. 1: Single cylinder rotation engine

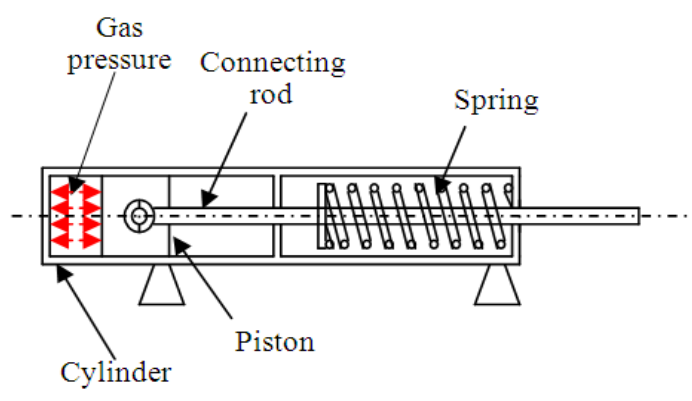

Fig. 2: Single cylinder linear engine

Based on the above background, the objective of this research is to predict engine performance, especially the combustion pressure characteristics and to study conventional engine performance to compare with linear engine performance. The final result of this study will be use as a design input data of a simple and small free piston linear engine with spring as return force of the piston movement technique.

Engine dynamics: In order to investigate the dynamics of reciprocating engine, it is necessary to analyze the dynamic forces, moments and torques in a machinery systems even it was simple mechanism. However, actually the mechanism is quite complex in terms of the dynamic consideration necessary to its design for high speed operation ${ }^{[4]}$. The different between a single cylinder rotation reciprocating engine with linear engine is in the process of return back to top dead center. However, a basic mechanism for engine rotation consists of a crank, a connection rod and a piston. On the other hand, the linear engine consists of spring, connecting rod and piston. This basic design has a large impact on an engine performance. Figure 1 and 2 are sketches of mechanisms of single cylinder rotation engine and linear engine respectively.

In the internal combustion engine, it should be fairly obvious that at most we can only expect energy to be delivered from exploding gases during the power stroke of the cycle. The piston must return to top dead center on it own momentum before it can receive another push from the next explosion. In fact, for rotation engine, the energy must be stored in crankshaft merely to carry it through the top dead center and bottom dead center points. In case for single cylinder linear engine the energy should be stored in spring. See also design mechanism at Fig. 1 and 2 .

According to linear engine, spring is most crucial design and need to be analyzed carefully. In rotation engine, the stroke is always the same in many operation conditions. Displacement of spring is depending on force; this spring should be traveling from bottom dead center to top dead center as needed on mostly operation condition. It means that a part or all of intake manifold should be open in order to transfer mixture; otherwise explosion in combustion chamber will not happen. Spring displacement is effected by piston speed and engine load. Both variables could result in explosion in combustion chamber; however, different explosion also produces different thrust force as the result displacement of piston movement is unstable.

The engine works as two stroke spark ignition and does not need any valve, though to increase its efficiency it is sometimes provided with a passive (pressure differential operated) one at the intake port. It requires only two strokes, to complete its cycle. There is passageway, called a transfer port, between combustion chamber above the piston and below crankcase. There is also an exhaust port in the side moves up and down. The crankcase is sealed and mounts the carburetor on it, serving also as the intake manifold. The combustion process of two strokes spark ignition linear engine exactly the same with rotation two strokes engine, so we do not need to explain the detail of the process.

The usable output torque is created from explosive gas pressure generated within the cylinder. The magnitude and shape of this explosion pressure curve will vary with the engine design, stroke cycle, fuel used, speed operation and other factors related to the thermodynamics of the system. For our purpose of analyzing the mechanical dynamics of the system, we need to keep the gas pressure function consistent while we vary other design parameters in order to compare the results of linear engine design.

\section{MATERIALS AND METHODS}

The predict engine performance without having to conduct test is call modeling ${ }^{[5]}$, GT-Power has been used for the simulation. The basic concept to predict engine performance using simulation is different with using engine experiment. Pressure diagram conducted 
first in experiment methods and then heat release can be analyzed, while for simulation is the opposite of the experimental method. There are two theories of heat release such as chemical theory and mathematical model using first law of thermodynamics. Both theories have been adopted in this research. Wiebe combustion model is chemical theory based, where the mass fraction burnt profile is represented as:

$$
x=1-\exp \left[a\left(\frac{t}{t_{\text {comb }}}\right)^{m+1}\right]
$$

After differentiation of Eq. 1, the rate of heat release $\mathrm{dt} / \mathrm{d}\left(\mathrm{t} / \mathrm{t}_{\mathrm{comb}}\right)$ is expressed as:

$$
\mathrm{w}=\mathrm{a}(\mathrm{m}+1)\left(\frac{\mathrm{t}}{\mathrm{t}_{\text {comb }}}\right)^{\mathrm{m}} \exp \left[\mathrm{a}\left(\frac{\mathrm{t}}{\mathrm{t}_{\text {comb }}}\right)^{\mathrm{m}+1}\right]
$$

Where:

$\mathrm{T}_{\text {comb }}=$ Period of combustion

$\mathrm{t}=$ Time variable of combustion process $0 \leq \mathrm{t} \leq \mathrm{t}_{\text {comb }}$ $\mathrm{a}, \mathrm{m}=$ Parameters

The parameter of a characterizes the completeness of combustion, while $\mathrm{m}$ is the rate of combustion. Wiebe assumed $\mathrm{x}_{\max }=0.990$ and hence $\mathrm{a}=6.908^{[6]}$. Value of $\mathrm{a}=5$ and $\mathrm{m}=3$ have been reported to fit well with experimental data ${ }^{[7,8]}$. Through Wiebe combustion model and then used first law of thermodynamics to substitute heat energy to pressure gradient of gas at combustion space. Equation 3 is expression of simple first law thermodynamics:

$$
\frac{\mathrm{dp}}{\mathrm{dt}}=-\gamma \frac{\mathrm{P}}{\mathrm{V}} \frac{\mathrm{dV}}{\mathrm{dt}}+\frac{\gamma-1}{\mathrm{~V}}\left(\frac{\mathrm{dQ}}{\mathrm{dt}}\right)
$$

This is a first order differential equation of the form $\mathrm{dp} / \mathrm{dt}=\mathrm{f}(\mathrm{t}$, PQ for cylinder pressure as function of time, $\mathrm{t}$, pressure, $\mathrm{P}$ and the heat release, $\mathrm{Q}$. By using the main formula the pressure diagram of combustion process in linear engine could be conducted.

The characteristics of pressure at combustion chamber between rotation engine and linear engine exactly the same. The different is that dynamics movement and resulted different power output. The engine friction reduces work of an engine and it is the difference between the indicated work and the brake work at power output. The friction process in an internal combustion engine can be categorized into three components such as the mechanical friction, the pumping work and the accessory research ${ }^{[5,7,8]}$. In case of linear engine, mechanical friction part can be reduced because it does not need rotation motion and only leaved piston ring and gas pressure components.

To predict power output of linear engine through simulation, the predict friction loss is very importance manner. Many methods have been developed to measure the engine friction loss including experimental and simulation techniques. A great effort have been made by researchers for developing comprehensive and accurate mechanical loss models: And different model approaches have been proposed ${ }^{[7,8]}$. Arsie, Pianese, Rizzo, Flora and Serra ${ }^{[9]}$ has proposed excellent formulas; however, it can not be adopted here. Although these formulas have a high precision level, the formulas difficult to break down on some parts especially to predict friction loss through crank shaft, pin and bearing. In case of linear engines, some devices could be ignored except connecting rod, piston and journals bearing.

According to GT-Power software using manual, the engine friction is calculated using the attribute as follow:

$$
\text { fmep }=C+\left(\operatorname{pfx} P_{\max }\right)+\left(\operatorname{mpsfx} \bar{U}_{\mathrm{P}}\right)+\left(\operatorname{mpssfx} \overline{\mathrm{U}}_{\mathrm{P}}^{2}\right)
$$

Where:

C = The constant part of the fmep $\mathrm{PF}=$ The peak cylinder pressure factor

mpsf $=$ The mean piston speed factor mpssf $=$ The mean piston speed squared factor

Following that expression, it is difficult to brake down in parts for friction components, but it is possible to use separate calculation using another expression. If the fmep is known, then using this data directly by inputting the data into constant part of fmep.

Atkinson, Patreanu, Clark, Atkinson, McDaniel, Nankumar and Famouri ${ }^{[10]}$ introduced a simple equation for calculate fmep of linear engine. However, this expression developed only based on friction from contacting between piston and cylinder liner. In fact, the effect of cylinder pressure and main bearing still happens. For that reason the formula was not be adopted in this research. The preceding component analysis can be combined to from an overall engine fmep model. The component equations are summarized by Ferguson and Kirkpatrick ${ }^{[7]}$ and have been used to develop a fmep model in this research. Some component equations, including valve train, pumping and accessory did not adopted in the present two stroke engine design. Although main bearing is differing between rotation and linear engine, however, this expression more closed to predict the friction losses on linear engine than Atkinson et al ${ }^{[10]}$ formula. Equations below are used in fmep modeling design simulation. 
Am. J. Engg. \& Applied Sci., 2 (4): 713-720, 2009



Fig. 3: Flow chart of the model design analysis

\section{Main bearings:}

$$
\text { fmep }_{\text {bearings }}=c_{b} \frac{n_{b} N D_{b}^{2} L_{b}}{n_{c} b^{2} s}
$$

Seal:

$$
\text { fmep } \mathrm{seals}_{\mathrm{s}}=\mathrm{c}_{\mathrm{s}} \frac{\mathrm{D}_{\mathrm{b}}}{\mathrm{n}_{\mathrm{c}} \mathrm{b}^{2} \mathrm{~s}}
$$

\section{Connecting rod bearing:}

$$
\text { fmep }_{\text {bearing }}=41.37 \mathrm{~K}\left(\frac{\mathrm{b}}{\mathrm{s}}\right)\left(\frac{\mathrm{N}}{1000}\right)
$$

and

$$
K=\left(D_{m b}^{2} L_{m b}+\frac{D_{c b}^{2} L_{c b}}{m}+D_{a s}^{2} L_{a s}\right) \frac{1}{b^{3}}
$$

\section{Skirt:}

$$
\text { fmep }_{\text {skirt }}=c_{p s} \frac{\bar{U}_{p}}{b}
$$

\section{Rings:}

$$
\text { fmep }_{\text {rings }}=c_{p r}\left(1+\frac{1000}{\mathrm{~N}}\right) \frac{1}{\mathrm{~b}^{2}}
$$

\section{Gas pressure:}

$$
\text { fmep }_{\text {gasload }}=\mathrm{c}_{\mathrm{g}} \frac{\mathrm{P}_{\mathrm{i}}}{\mathrm{P}_{\mathrm{a}}}\left[0.088 \mathrm{r}+0.182 \mathrm{r}^{\left(1.33-\mathrm{K} \overline{\mathrm{U}}_{\mathrm{p}}\right)}\right]
$$

Table1: Engine specifications

\begin{tabular}{llll}
\hline Sr. No & Parameter & Unit & Value \\
\hline 1 & Model & & $\begin{array}{l}\text { BG-328 } \\
2 \text { cycle, single cylinder, air } \\
\text { cooled, gasoline engine }\end{array}$ \\
& Type & & 36.0 \\
3 & Bore & $\mathrm{Mm}$ & 30.5 \\
4 & displacement & $\mathrm{Mm}$ & $0.81 / 6000$ \\
5 & Max output & $\mathrm{kW} \mathrm{rpm}^{-1}$ & Float type \\
6 & Carburetor & & IC ignition (solid state) \\
7 & Ignition system & & $\begin{array}{l}\text { Mixed fuel of gasoline and } \\
8\end{array}$ \\
Fuel & & 2 cycle oil at 25:1 \\
\hline
\end{tabular}

Equation 5-11 normally used for two stroke rotation spark ignition engine, but for linear engine some parts could be eliminated. In this research, the formula (5) has been used to predict friction losses in main bearing, formula (6) for seal, formula (10) for piston rings and formula (11) for gas pressure. On the other hand, friction losses at connection rod bearing and skirt have been ignored. Figure 3 is flow chart of modeling in this research.

According to flow chart at Fig. 3, GT-Power has been used as main model. To simulate linear engine, the fmep data has been simulated separately, then added in engine crank train mode, a part from friction constant. However, the simulation can not run automatically, so we need to conduct more than one load. For that, we should change fmep constant manually. A real engine specification has been used in this study. The main specifications of the engine are shown in Table 1 .

\section{RESULTS}

The main concern of the research is the prediction of performance of a linear engine and to design a real engine based on real rotation engine. The advantages of modifying from rotation engine to linear engine are reducing research budget and the ability of studying the comparison of both systems design which is an important thing. The main difference in performance is that friction mean effective pressure (fmep). However, performances at combustion chamber are exactly the same on both engines. In this research, parameter profiles of dynamics aspects were presented according to convention, but its convenient data are displayed by cycles. This is dedicated for linear engine, even touch the research also examined rotation engine as comparison study.

Logarithmic and P-V diagrams were used to express the pressure diagrams. The logarithmic scales to provide a rational interpretation of the profile presented by Fig. 4, their data are expressed in terms of analytic functions. The polytrophic exponents are evaluated, accordingly from these data as presented by 
least square fit regression for the processes of compression and expansion profiles were linear ${ }^{[11]}$. According to Heywood ${ }^{[8]}$ the start of combustion can be identified by the departure of the curve from the straight line. The end of combustion can be located approximately in similar fashion.

Figure 4 is logarithmic diagram introduce $\log \mathrm{P}$ versus $\log \mathrm{V}$ on variable speeds. The characteristics of engines at same condition introduce that maximum pressure increase from beginning to 2 then decrease until $6.1 \mathrm{~m} \mathrm{sec}^{-1}$. However, pressure degradations after $2 \mathrm{~m} \mathrm{sec}^{-1}$ are smaller than before $2 \mathrm{~m} \mathrm{sec}^{-1}$. Figure 5 is a comparison of $\mathrm{P}-\mathrm{V}$ diagram at critical characteristics. Different characteristics of the three graphs are clearer from this Fig. 5. In case $6.1 \mathrm{~m} \mathrm{sec}^{-1}$, the pressure at the end of stroke is still high. It means that energy is high at the end of stroke, however, exhaust port already opened as the result reducing volumetric efficiency. From Fig. 5 it can be shown that maximum pressure starts from 36.34 bar at 0.5 than goes to 45.79 bar at 2 and finally drop to 26.56 bar at $6.1 \mathrm{~m} \mathrm{sec}^{-1}$. The lowest and the highest of pressure maximum different is very contrast.

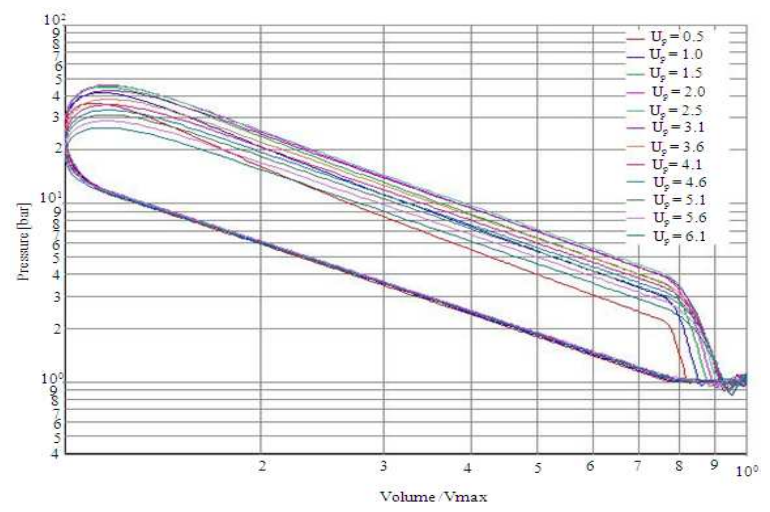

Fig. 4: Log P-log V diagram on variable speed

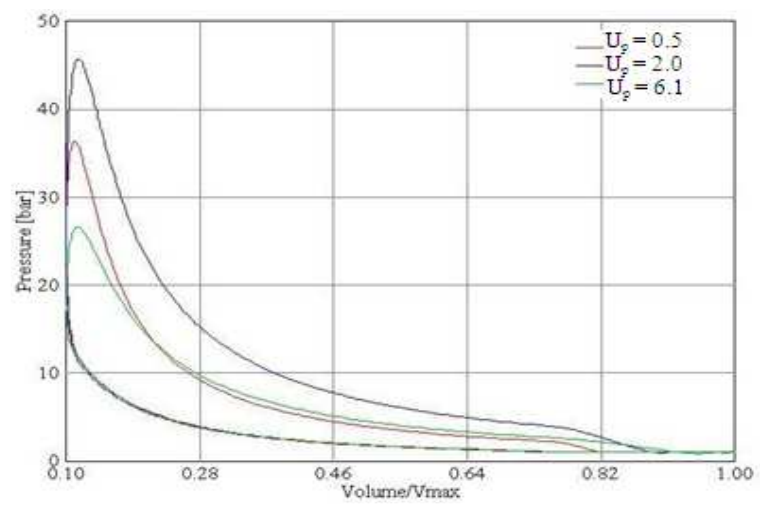

Fig. 5: P-V diagram at critical characteristics
Figure 6 shows a comparison between a rotation engine and linear engine. According to rotation friction loss graph trend is reduced from beginning till $1.5 \mathrm{~m} \mathrm{sec}^{-1}$ then dramatically increased. On the other hand, for linear engine, it decreased systematically from beginning then become little bit stable after $4.1 \mathrm{~m} \mathrm{sec}^{-1}$.

The brake power was obtained by cut down the friction losses from the indicated power. The characteristics of an engine are shown in Fig. 7. At low speed, the difference between rotation and linear engine was not significant, but after $1.5 \mathrm{~m} \mathrm{sec}^{-1}$ the gab of both lines increased. According to rotation engine, after $4.1 \mathrm{~m} \mathrm{sec}^{-1}$ the power dropped systematically. In case of linear engine, although after $5.1 \mathrm{~m} \mathrm{sec}^{-1}$ dropped but still understood. This performance causing by friction losses after $4.1 \mathrm{~m} \mathrm{sec}^{-1}$ was stabile as a result the power dropped was small.

Torque is good indicator of an engine ability to do work. The characteristics both linear and rotation engines are shown at Fig. 8. According of graph in the Fig. 8 both linear and rotation engines have same trend. The point of maximum torque is in piston speed of $2.5 \mathrm{~m} \mathrm{sec}^{-1}$. However, torque of linear engine is higher than rotation engine.

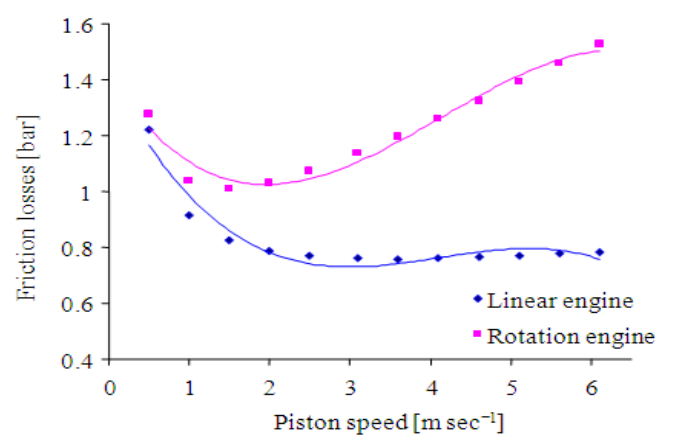

Fig. 6: Comparison of friction loss between rotation and linear engine

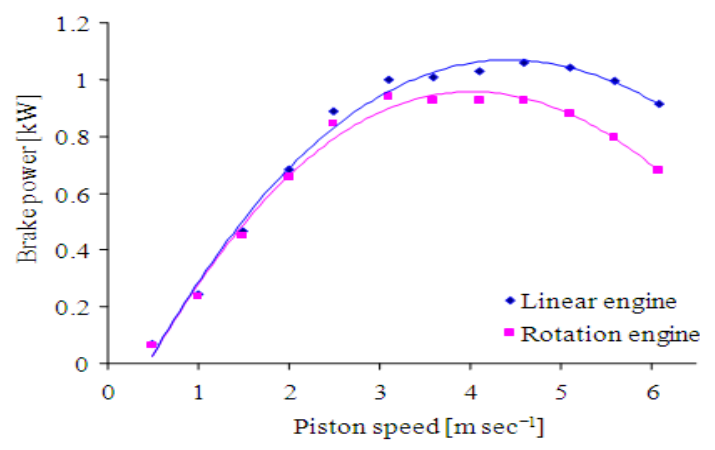

Fig. 7: Comparison of brake power between rotation and linear engine 
Am. J. Engg. \& Applied Sci., 2 (4): 713-720, 2009

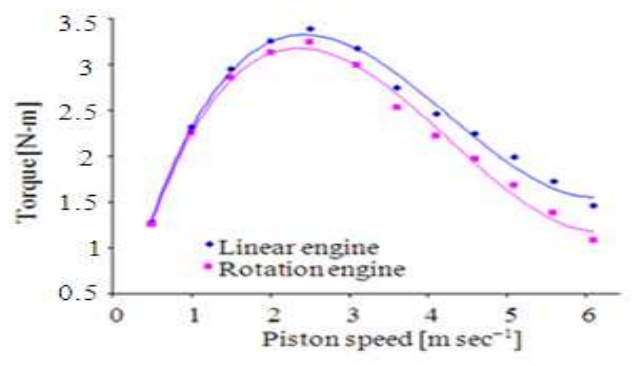

Fig. 8: Torque of both linear and rotation engines on variable speeds

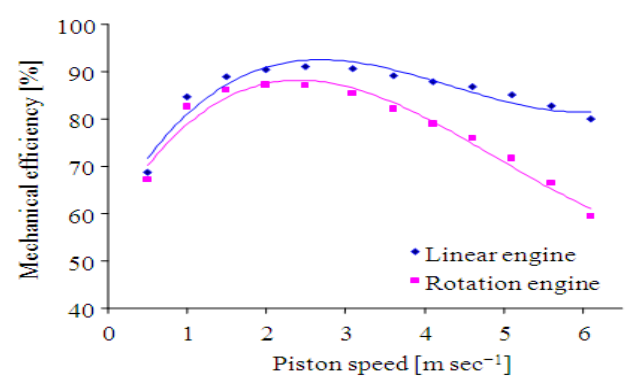

Fig. 9: The mechanical efficiency of both linear and rotation engines Vs variable speeds

Mechanical efficiency is conducted by the ratio of brake work at crankshaft to indicated work in the combustion chamber. Excluding parasitic loads, the mechanical efficiency of the rotation engine is between $59.4-87.1 \%$. Beginning in $67.2 \%$ at piston speed $0.5 \mathrm{~m} \mathrm{sec}^{-1}$ then increased to $87.1 \% 2 \mathrm{~m} \mathrm{sec}^{-1}$ after then gradually decreased until $59.4 \%$ at $6.1 \mathrm{~m} \mathrm{sec}^{-1}$. The mechanical efficiency of linear engine is between 68.8$91.1 \%$. Beginning with $68.8 \%$ at $0.5 \mathrm{~m} \mathrm{sec}^{-1}$ and increased to $91.1 \%$ at $2.5 \mathrm{~m} \mathrm{sec}^{-1}$ and dropped to $79.9 \%$ at $6.1 \mathrm{~m} \mathrm{sec}^{-1}$. Figure 9 shows the characteristics of mechanical efficiency of both rotation and linear engines. The greatest losses energy at high speed engines reduced the mechanical efficiency, while heat loss is the greatest loss at low speeds ${ }^{[15]}$.

Fuel consumption is one of the most important characteristics of the engine performance; to get a good improvement is much have better in fuel consumption properties. Figure 10 is comparison result of brake specific fuel consumption between rotation and linear engine. Same think with other performance, the characteristics of fuel consumption of linear engine is better than rotation. The improvement of brake specific fuel consumption is between $3.2-25.7 \%$. The average improvement is about $11.2 \%$. The economist area linear engine is in between 2-5.1 and 2-4.1 m sec${ }^{-1}$ for rotation engine. The minimum oil consumption is about 297.9 for linear engine and $323.6 \mathrm{~g} \mathrm{k}^{-1} \mathrm{~W} \mathrm{~h}$ for rotation engine.

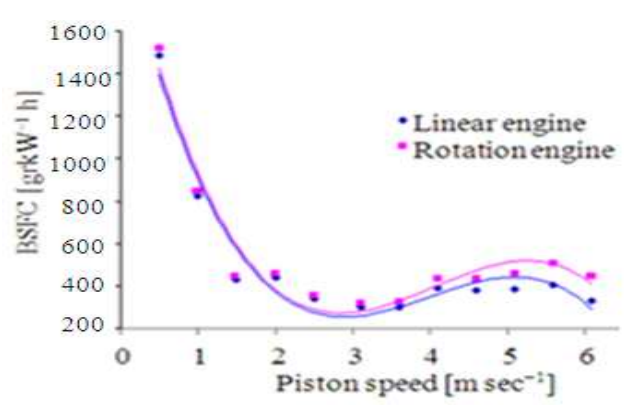

Fig. 10: Comparison of brake specific fuel consumption between rotation and linear engine

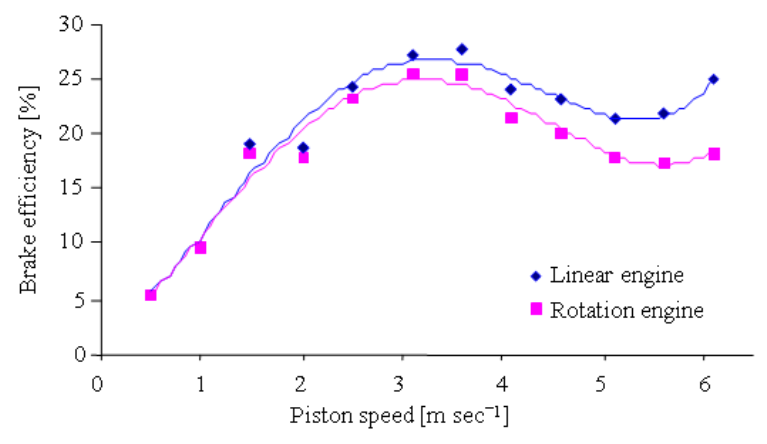

Fig. 11: Brake efficiency of linear and rotation engines Vs variable speeds

The brake efficiency of both linear and rotation engines can be shown at Fig. 11. The greatest brake efficiency is at piston speed of $3.6 \mathrm{~m} \mathrm{sec}^{-1}$. However, after dropped at 5.6 then the efficiency were increased again at $6.1 \mathrm{~m} \mathrm{sec}^{-1}$. This phenomena causing by mass flow of fuel and power were decreased at $6.1 \mathrm{~m} \mathrm{sec}^{-1}$, but the trend of both parameter were not parallels as the result brake efficiency was increased.

Focusing on main objectives of this research is to design a real linear engine with spring as return cycle. To design the spring, it is needed an optimization of thrust force of the piston. Figure 12 is a prediction of maximum pressure on variable pressure at full load of engine performance. At beginning of speed the maximum pressure was $36.3 \mathrm{bar}$, then become maximum about 45.8 bar at $2 \mathrm{~m} \mathrm{sec}^{-1}$ after all degradation fall until $26.7 \mathrm{bar}$ at $6.1 \mathrm{~m} \mathrm{sec}^{-1}$. The variable of maximum pressure ware fluctuated, especially different between minimum and maximum pressure was high. To discuss correlations between engine load, speed and maximum pressure is complicated. There are so many theory effecting performance and characteristics of the engine. Pressure could be related with the crank angle at which this maximum pressure occurs, the maximum pressure rise and so many correlated could be analysis. 


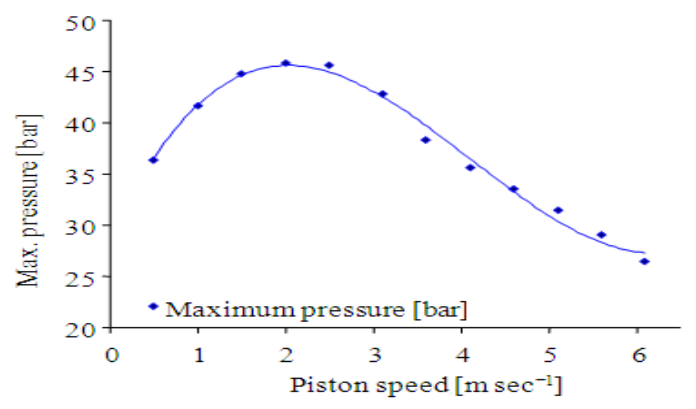

Fig. 12: The characteristics engine on maximum pressure of variable speed

The rate of change of pressure is substantially affected by the rate of change of cylinder volume as well as rate of burning, change in the pashing of the combustion process ${ }^{[8]}$. Slow burning and fast burning related with speeds and loads also have correlated with occurring maximum pressure. The quantity of fuels burn at premixed combustion also contributed the maximum pressure. According of Fig. 12 maximum pressure occurred at $2 \mathrm{~m} \mathrm{sec}^{-1}$, it is much affected by the quantity of fuels burnt at premixed combustion was highest as the result highest maximum pressure. The other hand, combustion rates at high speed were gradually and resulted smaller maximum pressure. Back to main objectives of using spring as return cycle, based on the maximum pressure data the spring could be design specifically. But need to study independently on specific topic.

\section{DISCUSSION}

Combustion pressure is one of an important performance to discuss. Related with combustion pressure performance result is complicated, it is because have been effected by many variables and could not explain only case by case. This performance is important to design the spring for return cycle in linear engine. However, trend of pressure is scattered from small at low and high speed and high at medium speed. If it is correlated to optimization of spring design for spring system in linear engine it needs analysis carefully.

Friction work is defined as the difference between the works transferred to the piston from the gas contained inside the cylinder and work available at drive shaft. The analysis of friction losses is an important aspect to consider during the design process because the main difference between a good engine design and average design often is the difference in their friction losses ${ }^{[12]}$. Figure 6 is comparison of friction between linear and rotation engine. The main difference of these graphs causing by the skirt. However, a friction loss of skirt is depending on average velocity of the piston. According to Ferguson and Kirkpatrick ${ }^{[7]}$ and see also on Eq. 9, that formula is correlated with boundary lubrication viscosity, bore of the piston and average velocity of the piston. Moreover, Patton, Nitschke and Heywood ${ }^{[13]}$ suggested a proportionality constant $\mathrm{C}_{\mathrm{ps}}=294 \mathrm{kPa} \mathrm{mm} \mathrm{sec} \mathrm{m^{-1 }}$. In case of the linear engine, for skirt friction, it was ignored because the rotations do not work in this engine. However, in general designs of piston assembly were not skirt connector in linear engine ${ }^{[14]}$.

The main objective to develop linear engine is increasing brake power and performance in Fig. 7 is very clear. Comparing with another research result, both trends have similar performance. Heywood ${ }^{[8]}$ and Stone $^{[7]}$ also reported that performance characteristics of small two stroke engine have maximum power at about $4.1 \mathrm{~m} \mathrm{sec}^{-1}$ and smaller motor cycle engine can achieve slightly higher bmep and higher speeds. According engine specification at Table 1, the maximum power is different. However, maximum power in engine specification at $6000 \mathrm{rpm}\left(6.1 \mathrm{~m} \mathrm{sec}^{-1}\right)$ is $0.81 \mathrm{~kW}$. In this research is about $0.93 \mathrm{~kW}$ at $4.6 \mathrm{~m} \mathrm{sec}^{-1}$. At same speed on $6.1 \mathrm{~m} \mathrm{sec}^{-1}$ was about $0.7 \mathrm{~kW}$ for rotation engine. In case maximum power of linear engine is totally different because target of improvement of the research is to increase power output from the engine. The improvement power output increased between 2.3-34.6\% and the average improvement is about $13.8 \%$. In this study an excellent improvement is at high speed engine performances. At low speeds, improvement is not too strong as high speeds performance.

Normally brake specific fuel consumption as function of engine speed. Brake specific fuel consumption decreases as engine speed increases, reaches a minimum and then increases at high speeds. Fuel consumption increases at high speed because of greater of friction losses. At low engine speed, the longer time per cycle allows more heat loss and fuel consumption goes up ${ }^{[15]}$. According to Fig. 6, the friction loss of rotation engine is high at high speed and this result impacting of the fuel consumption increases. Brake specific fuel consumption also effected by fuel equivalence ratio. Based of the research result the fuel equivalence ratio between 2.5-6.1 $\mathrm{m} \mathrm{sec} \mathrm{se}^{-1}$ unsystematically fluctuation, those impacted brake specific fuel consumption at high speed as a Fig. 10.

Brake efficiency in Fig. 11 is very clear result. However, this result has different trend comparing with Mikalsen and Roskilly ${ }^{[16]}$. The free piston engine has a slight efficiency advantage over the conventional 
engine at low speeds but drops as the speed increases. This is could be compromises because the performance of an engine can be affected by configuration of engine design.

\section{CONCLUSION}

Prediction of the performance of linear engine with spring has been studied in this research. To predict brake power of linear engine, the friction losses were simulated separately using GT-power software. However, the result is clear and comparing with rotation engine all of performances introduce strong improvements especially at high speed operation. Friction losses could be reduced dramatically, as the result of power output could be increased. Specific fuel consumption also could be reduced specially at high speed operations, this result causing by reducing friction losses and change the energy to contribute the power output of an engine.

The prediction of combustion pressure at variable speed is very importance result in the research. Although the area of pressure maximum fairly different it is still possible to design spring as return cycle in the linear engine. Related with combustion pressure performance result is complicated, it is because have been effected by many variables and could not explain only case by case.

In general results of the research could be adapted to design a real linear engine specially to simulate design spring as return cycle. Based on prediction a weakness of original engine design, it is possible to modify improvement system design.

\section{ACKNOWLEDGMENT}

The present research is funded by Grant of Research Students, University Malaysia Pahang (GRS 070123). Special thanks to Mr. Ismail Ali for assisted research preparation.

\section{REFERENCES}

1. Goertz, M. and 1. Peng, 2000. Free piston engine its application and optimization. SAE Technical Paper Series 2000-01-0996. http://www.sae.org/technical/papers/2000-01-0996

2. Nag, P.K., 2002. Power Plant Engineering. 2nd Edn. McGraw Hill Higher Education, ISBN: 0071211101, pp: 786-787.

3. Mikalsen, R. and A.P. Roskilly, 2007. A review of free-piston engine history and applications, Applied Therm. Eng., 27: 2339-2352. DOI: 10.1016/j.applthermaleng.2007.03.015
4. Robert, L.N., 2004. Design of Machinery: An Introduction to the Synthesis and Analysis of Mechanisms and Machines. 3rd Edn., McGraw Hill, ISBN: 0071214968, pp: 858.

5. Richard, S., 1997. Introduction to Internal Combustion Engine. Society of Automotive Engineers, 2nd Edn., ISBN: 9780333740132, pp: 274-293 and pp: 361-396.

6. Kowalewicz, A., 1984. Combustion Systems of High-Speed Piston I.C. Engine. Elsevier Science Publishers, Amsterdam, Netherlands, ISBN: 9780444996374, pp: 365.

7. Colin, R.F. and A.T. Kirkpatrick, 2001. Internal Combustion Engine Applied Thermosciences. 2nd Edn., Jon Wiley and Sons, ISBN: 9780471356172, pp: 384.

8. John, B.H., 1988. Internal Combustion Engine Fundamentals. McGraw Hill Book Company, ISBN: 13: 9780070286375 , pp: 930.

9. Arsie, I., C. Pianese, G. Rizzo, R. Flora and G. Serra, 1998. Development and validation of a model for mechanical efficiency in a spark ignition engine. SAS Trans., 108: 1312-1323. http://cat.inist.fr/?aModele $=$ afficheN\&cpsidt $=16401745$

10. Atkinson C.M., S. Patreanu, N.N. Clark, R.J. Atkinson, T.I. McDaniel, S. Nankumar and P. Famouri, 1999. Numerical simulation of a two-stroke linear engine-alternator combination. SAE Technical Paper Series. 1999-02-0921. http://www.sae.org/technical/papers/1999-01-0921

11. Antoni, K.O., 2006. Dynamics of Combustion Systems. 1st Edn., Springer-Verlag. Berlin, Heidenburg, ISBN: 10: 3540326065, pp: 259.

12. Macro, P.N., 1998. Emission from Two-Stroke Engines. Society of Automotive Engineers. USA., ISBN: 076800215X, pp: 283.

13. Patton, K.J., R.G. Nitschke and J.B. Heywood, 1989. Development and evaluation of a friction model for spark ignition engine. SAE paper 890836. http://www.sae.org/technical/papers/890836

14. Achten, P.A.J., J.P.J. Vanden Oever, J. Potma and GEM Vael, 2000. Horspower with brains: The design of the Chiron free piston engine. SAE Technical Paper Series. 2000-01-2545. http://www.sae.org/technical/papers/2000-01-2545

15. Willard, W.P., 2004. Engineering Fundamentals of the Internal Combustion Engine. 2nd Edn., Pearson Prentice-Hall, USA., pp: 410-428.

16. Mikalsen, R. and A.P. Roskilly, 2008. Performance simulation of a spark ignited free-piston engine generator. Applied Therm. Eng., 28: 1726-1733. DOI: 10.1016/j.applthermaleng.2007.11.015 